\title{
INFORMATION DISORDER, THE TRIUMVIRATE, AND COVID-19: HOW MEDIA OUTLETS, FOREIGN STATE INTRUSION, AND THE FAR-RIGHT DIASPORA DRIVE THE COVID-19 ANTI- VACCINATION MOVEMENT
}

\author{
Aman Bajwa, BTech Crime and Intelligence Analysis, British Columbia \\ Institute of Technology, Canada
}

\begin{abstract}
Information disorder has become an increasing concern in the wake of the 2016 US presidential election. With the state of the COVID-19 pandemic rapidly evolving in all facets, the vaccination debate has become increasingly polarized and subjected to a form of politics based around identity markers such as nationality, ethnicity, gender, and ideology. At the forefront of this is the COVID-19 anti-vaccination movement that has gained mainstream attention, leading to conflict with pro-vaccinationists. This has paved the way for exploitation by subversive elements such as, foreign state-backed disinformation campaigns, alternative news outlets, and right-wing influencers who spread false and misleading information, or disinformation, on COVID-19 in order to promote polarization of the vaccine debate through identity politics. Disinformation spread sows confusion and disorder, leading to the erosion of social cohesion as well as the potential for real-world conflict and violence. As a result, the article below will generate further understanding of the modern-day spread of disinformation, the strategies and tactics utilized by state and non-state actors, the effects of its exposure, and the social-psychological processes involved in its spread and resonance. Furthermore, in countering this phenomenon, this article recommends a collaborative framework involving emphasis on critical media literacy skills, citizen participation, and development of counter-offensive capabilities towards state-backed information operations.
\end{abstract}

\section{Introduction}

Since the 2016 U.S. presidential election, the anti-vaccination movement has developed significant momentum, rising from obscurity as a fringe movement, to becoming a salient political actor within the public eye (Bernard et al., 2021). This rise has been expedited by the COVID-19 crisis that, along with barriers associated with enforcing COVID-related health and safety guidelines, has also brought to the forefront different types of politics based on an intersection of attributes such as race, class, ideology, and gender (Broniatwoski et al., 2020; Dornan, 2020; Walter et al., 2020). As a result, the movement has become primed 
towards viewing the issue of the COVID-19 epidemiology and its corresponding issue of vaccine development through the lens of "identity politics" because of the spate of misinformation and disinformation being disseminated by actors with various motives (Broniatowski et al., 2020; Walter et al., 2020). Much of this priming has been carried out by influencers from the far-right, politicians, hyper partisan and mainstream news outlets, and a Kremlin-backed disinformation campaign (Canadian Security Intelligence Service [CSIS], 2016; Marwick \& Lewis, 2017; Walter et al., 2020). As such, this article will attempt to delve into the role of disinformation within the anti-vaccination movement, as well as the tactics and strategies utilized for spreading disinformation over social media, a major vehicle for information warfare by contesting state and non-state actors. In addition, the article will analyze the roles played by the 'Triumvirate', a term conceptualized by Hotez (2020) on the escalating nature of anti-science extremism. Whereas he referred to the triumvirate as those entities responsible for the growth of anti-science extremism; this article, for its purposes, will refer to the triumvirate as being composed of three primary actors: mainstream/hyper partisan news outlets, Russian intelligence-controlled channels, and far-right influencers and social media users. Analyzing how these actors contribute to the spread of false or misleading information, and their motivations behind it, will provide the readership with a better understanding of the production and consumption processes that make up the trajectory of disinformation spread over social media. Most importantly, analyzing the effects of disinformation will provide a glimpse into how it influences user sentiment and perception of issues; issues that are prone to partisanship, and therefore, manipulation by disinformation agents with subversive intents. Following this qualitative analysis, a list of recommendations and solutions will be given for countering disinformation tactics while developing greater resiliency in the face of it.

This first section will go into the contemporary history of disinformation and how it first became noticed in the public eye. At the same time, a definition based upon scholarly consensus will be established that unpacks the term, 'disinformation', while also distinguishing it from other terms such as, 'misinformation' and 'malinformation'; terms that tend to be used interchangeably but have been found to have different characteristics and intentions behind their spread online. The second section will go further into the different motivations of the actors involved in developing and perpetuating the spread of disinformation over online networks. It will also delve into the different tactics and strategies utilized by state and independent actors, and how these ultimately aid the COVID-19 anti-vaccination movement's goals in promoting fear and distrust of the global health and safety infrastructure. The third section

The Journal of Intelligence, Conflict, and Warfare Volume 4, Issue 2 
will utilize Cognitive Dissonance Theory, Affect Theory, and Social Identity Theory to explain how disinformation and misinformation resonates with online users, making them susceptible to influence, and what the consequences of this influence of user affect and cognition entails. Finally, the last section will outline recommendations and solutions at the state and technological level in combatting disinformation actors and operations, as well as mitigating its spread and influence.

\section{Modern spread of politicized disinformation in a post-truth world}

Scholars from the field of digital media and communications generally concur that disinformation can be defined as any false or misleading information that is spread with the intent of deceiving and sowing confusion and disorder (Broniatowski et al., 2020; CSIS, 2016; Guess \& Lyons, 2020; Wardle \& Derakhshan, 2017). Its close counterpart, misinformation, while similar, is defined as information that is false or misleading, but is not spread with the intention of causing harm. Distinct from these in terms of authenticity, is malinformation, which can be seen as any truthful information that has been leaked for the purposes of causing reputational damage. The hacking of Hillary Clinton's emails by Russian cyber agents would be an example of this (Wardle $\&$ Derakhshan, 2017). For the purposes of this article, only disinformation and misinformation will be focused on.

While the origin of disinformation goes back centuries, its contemporary form has become more noticeable in the wake of the 2016 presidential election (Dornan, 2020). Originally coined by the KGB during the Soviet era, disinformation was considered by the former Soviet Union as a harmful form of propaganda that was based upon false narratives and contexts, geopolitics, and nationalistic sentiment. As a necessary tool in their operational planning, one that was based on the 'Active Measures' policy and Gerisomov Doctrine, the intent was to sow division and discord in enemy nation-states by obfuscating the origin of the disinformation and attributing its spread to third parties (CSIS, 2016; Lin $\&$ Kerr, 2018). Since 2008, the Kremlin has utilized disinformation campaigns in countries such as Georgia, France, Ukraine, United Kingdom, and the Baltic states. There is no doubt, however, that their biggest success in recent years has come from interfering in the U.S presidential election in which Donald Trump prevailed (CSIS, 2016; Lin \& Kerr, 2018). This has been the result of both learning from past campaigns that have targeted foreign elections, and the rhetorical tactics that the Trump campaign used to bolster the success of their candidate in the months leading up to the election, and even afterwards (CSIS,

The Journal of Intelligence, Conflict, and Warfare Volume 4, Issue 2 
2016). These conditions had a profound impact on the electorate's ability to discern truth from falsehood and have led to a cascading effect on political discourse over social media leaving little room for middle grounds.

The 2016 U.S. election campaign was referred to as the most polarized campaign to date in the past 25 years (Doherty \& Kiley, 2016). As a result of Trump's rhetoric, the campaign was notably marked by xenophobic sentiments, white nationalism, anti-globalism, and support for an 'America First' isolationist policy that was defined by tougher negotiations with NATO allies, further trade barriers, and immigration restrictions (Beauchamp, 2016; Nelson, 2016). This led to frequent clashes between Democrats and Republicans, which occurred across social media platforms and at offline protests that occurred at Trump's political rallies, covered by the mainstream media. The biggest effect on polarization, and the one most conducive to the spread of disinformation online, was seen in Trump's frequent attacks on mainstream media outlets such as CNN, in which he referred to them as 'fake news' (Bernard et al, 2021). Mainstream media (or legacy) outlets have traditionally been viewed as the gatekeepers from which information is passed top-down, due to the code of ethics that many professional journalists are bound by, one that requires them to fact-check and corroborate sources to maintain credibility (Bennett \& Livingston, 2018; CSIS, 2016; Kharroub, 2019). However, even mainstream media can contribute to disinformation spread as Obama's first term as president showed. During this period, efforts were made to debunk false narratives spun by the birther movement regarding Obama's birth status. This inadvertently led to a media amplifying effect, however, as false narratives were amplified to resonate with supporters (Bennett \& Livingston, 2018; Global Engagement Centre [GEC], 2020). Through the influence of figures such as Donald Trump, both the legacy media and the alternative-media continued to amplify the false narrative created by the birther movement to nullify Obama's candidacy, despite evidence debunking it. The created media amplification, thus, "fed back through mainstream and alternative communication channels as a disruptive and disorienting reverberation, reaching mainstream audiences" (Bennett \& Livingston, 2018, p. 124).

As this example implies, this type of continued amplification of already debunked narratives can lead to growing distrust by mainstream media consumers, leading them to turn to alternative news sources; hence, satisfying these source's aims of undermining the mainstream media's credibility (Marwick $\&$ Lewis, 2017). Therefore, a major element of alt-media is seen in its purpose to create ideologically driven counter-narratives to the mainstream media. By

The Journal of Intelligence, Conflict, and Warfare Volume 4, Issue 2 
utilizing a cost-effective economic model for content production, alt-media producers can use low-cost online tools to produce alternative conspiratorial narratives that challenge mainstream media news about politics or breaking events (CSIS, 2016; Starbird, 2017). The popularity of such conspiracy theories has led to Alternative Media Personalities (AMPs) taking advantage of early coverage of the pandemic to supply conspiratorial misinformation to their online far-right audiences (Kelvin, 2021). Far-right AMPs that take advantage of internet technologies can amplify risk perceptions, as they avoid journalistic balance in their coverage, and instead, opt to conspiratorially reframe risk communications that solidify their audience's worldview towards radical discourses such as anti-vaccination and climate change (Kelvin, 2021). In terms of its ecosystem, Marwick and Lewis (2017) find that the alt-media, within the context of anti-vaccination discourse, is comprised of a far-right network of hyperpartisan news outlets, dedicated to the peddling of conspiracy theories, rumours, misinformation, and mainstream media attacks, and motivated by nationalism, their embeddedness in internet culture, the desire to win the culture war against the Left, and an antipathy towards leftist ideals such as multiculturalism, feminism, racial tolerance, and political correctness. Based on the elements described, the alternative media can be conceptualized as: an online far-right media ecosystem that relies on low cost tools of production to produce online disinformation and misinformation on partisan issues such as antivaccination in order to promote polarization between the Left and the Right, and distrust of mainstream news authority through the Disinformation-AmplificationReverberation cycle which results in mainstream news reporting on false narratives that inadvertently amplify, and then reverberate back to audiences. Three examples that fall within the encapsulated definition are Breitbart, Infowars, and The Gateway Pundit. All three drew considerable support from the far-right during the presidential election of 2016.

Like the 2008 U.S. election, the media environment during both the 2016 election and Trump Presidency became prone to similar manipulations due to Trump's influencer status. Trump's attempts at de-legitimizing the mainstream news industry and conversely raising the prospect of 'alternative facts' brought the empirical reality of facts into question, inducing within his followers the idea of 'post-truth' - that there were multiple truths, rather than one objective way of looking at it (Guadagno \& Guttieri, 2019; Temmerman et al., 2018). When combined with "post-democratic processes" (Bennett \& Livingston, 2018, p. 127), it is not hard to conceptualize why disinformation and misinformation spread by online personalities and outlets with dubious credentials and expertise, have become popular with right-wing online users who adhere to the post-truth

The Journal of Intelligence, Conflict, and Warfare Volume 4, Issue 2 
view. Disinformation allows one to bypass the objectivity of information, while framing the contextual nature of it within a narrative or set of narratives that have no evidence to support it but are appealing to one's identity. By connecting with issues presented in an ideological, racial, or nationalistic framework, the recipient (i.e., the reader that agrees with Trump's politically charged rhetoric) is more likely to connect with Trump's position from an identitarian perspective rather than a rationalist one.

Trump's success in mobilizing the far right and creating an opposition to mainstream press is further indicative of his persuasive ability to weaponize disinformation, labelling all inconvenient coverage by the legacy media as 'fake news' (Guadagno \& Guttieri, 2019; Marwick \& Lewis, 2017). Such frequent attacks have resulted in a widespread decline in confidence by his supporters in the mainstream media and public officials, leading to a push for politically divisive discourse that promotes in-group consolidation, while undermining the out-group (Li \& Su, 2020; Wardle \& Derakshan, 2017). This phenomenon has been seen in both left-wing and right-wing individuals as research on fake news utterances over Twitter have shown. $\mathrm{Li}$ and $\mathrm{Su}$ (2020) found, from analyzing disconnected retweeted networks between 2016-2018, that there was an uptrend in identity-based language in fake news discussions over Twitter, which promoted in-group collectivity and consolidation by selectively amplifying messages while derogating the out-group by attributing blame. Furthermore, another major effect of Trump's rhetoric has been the heightened focus of news consumers on fake news stories from alternative news outlets over social media. As Twitter research study by Buzzfeed has shown, three months prior to the election, "20 top-performing fake news stories generated 8.7 million shares, reactions, and comments, while 20 top-performing stories from reputable news outlets generated a total of only 7.3 million" (Silverman, 2016, as cited by Tucker et al., 2018, p. 37-38). Despite only an 18\% difference, research by Bastick (2021) on covert modification of implicit attitudes has found that even miniscule exposure to positive disinformation can have an unconscious effect on consumers. In the controlled experiment, it was found that the largest effect, an increase of $5.15 \%$ came from the group that viewed the positive fake news article (Bastick, 2021, p. 6). Although a seemingly minor increase, this may contribute to greater swing voting. As Bastick (2021) states, real world disinformation campaigns are likely to have a larger effect as users are exposed to additional disinformation that is reinforced by multiple sources and influenced by peer endorsement; thus, if every eligible voter had been exposed in the past to a real world campaign that had anconscious effect of at least $5.15 \%$ this would've been sufficient enough to "flip the margin of the popular vote in the last two

The Journal of Intelligence, Conflict, and Warfare Volume 4, Issue 2 
presidential elections" (p. 7). As a result, it is apparent that the proliferation of disinformation combined with decreasing confidence has ominous implications for future elections.

This lack of confidence appears to be significantly prevalent within those on the authoritarian right, even though research indicates that social media discourse is fueled by voters at both ends of the spectrum. For the far-right, liberal democratic values are seen as the antithesis of movement values of ethnic nationalism and the restoration of "mythical cultural traditions" (Bennett \& Livingston, 2018, p. 125). In addition to this, research shows that there is a divergence in beliefs between the center-right, conservatives, and the more recently formed, 'alternative-right', or alt-right for short. The alt-right in particular appears to tilt more towards "strategic partisan disinformation" (Bennett \& Livingston, 2018, p. 125) due to their affinity for information sites that mimic journalistic authenticity by reporting on documented events, but ultimately emphasize disinformation aimed at destabilizing opponents and institutions (Bevensee \& Ross, 2019). Hence, for the purposes of this article, the alt-right can be conceptualized, under an essentialist approach, as a social-media driven far-right diaspora, characterized not only because of its shared cultural history and strict adherence to traditions and normative behaviors, but also its penchant for engaging with disinformation disseminated by the right-wing media ecosystem over online channels, through which it mobilizes (Feron \& Lefort, 2018; Ragazzi, 2012).

\section{Disinformation techniques, tactics, strategies, and its effect on the anti- vaccination movement}

Disinformation spread among the far-right takes on many forms, but in almost all cases the origin of the spread tends to be concealed due to the different phases involved in the transmission of a message. Compared to top-down forms of media transmission, this form of "ritualized" communication also works as a multiplier, leading the message to be transmitted from the bottom-up. This benefits the COVID-19 anti-vaccination movement in several ways. First, it anonymizes the creators of the disinformation narratives and products, leaving other agents, such as blog creators to shape and influence it as it crosses networks. Bevensee and Ross (2019) have found that this can be best exemplified by "refraction", a trend seen in conspiracy networks supporting Russian geopolitical objectives in Syria, which reproduce the same message through different political perspectives to give the illusion of agreement from a heterogenous plurality, even though these perspectives, which come from different blogs, are often connected to a single

The Journal of Intelligence, Conflict, and Warfare Volume 4, Issue 2 
organization. A similar trend has been found in research on COVID-19 antivaccination discourses online, wherein, investigations into Chinese and Russian disinformation campaigns has linked Twitter content polluter accounts to Chinese and Russian-backed narratives which paint the coronavirus epidemic as the result of the U.S creating a biological weapon for the purpose of damaging China economically (Bernard et al., 2021, p. 5). Through a technique known as "astroturfing" - a deceptive ploy that aims to give the false perception of grassroots support to an issue for the purpose of misleading the public into believing that their opinion is shared by most people-Russian disinformation agents can create artificial tweets that masquerade as grassroots advocacy for vaccine refusal which can be retweeted many times over by real advocates (Longley, 2020; Walter et al., 2020a). Astroturfed narratives can create an obstacle to independent thinking since they promote bandwagoning, or the desire to follow the majority (Longley, 2020). As a result of this effect by foreign actors, astroturfed narratives have aided the anti-vaccination movement's resurgence, allowing it to have become normalized as apart of mainstream discourse due to its narratives being picked up by the right-wing media ecosystem, and becoming key sources of information for Republicans (Bernard et al., 2021, p. 5). Thus, this shows how refraction can work to the anti-vaccination movement's advantage.

A second benefit relates to the use of other disinformation dissemination techniques such as Kremlin-backed trolls and bots. Trolls, to begin with, are the bread and butter of Kremlin disinformation campaigns, because of their role (or roles) in taking one or more sides of a debate and polarizing it by exploiting racial and gendered divisions, such as what a troll factory associated with the Internet Research Agency (IRA), a Russian intelligence linked agency, did over social media in 2016 (Guadagno \& Guttieri, 2019; Walter et al., 2020b; Young, 2021). By exploiting underlying societal tensions surrounding gender, race, and ideology, trolls contribute to fearmongering, partisanship, and divisiveness through the spread of "grey propaganda" (Young, 2021, p. 4). Freedman et al. (2021) in her article on hybrid threats and disinformation goes further in identifying other significant identity markers such as nationality, ethnicity, class, religion, and sexual orientation, emphasizing the importance of mitigating the destabilizing effects of grey propaganda, referring to "gray zone conflict" (p. 45), or the environment where grey propaganda is being spread for the purposes of influencing public opinion. In her view, developing mitigation strategies to curb the destabilizing effects of grey propaganda must take priority due to the potential for it to spark a real war if democratic legitimacy is believed to be compromised and the political structure "is seen as not representative of certain ideologies or politics" (p. 52). Thus, policymakers should not underestimate the role of 
foreign-backed trolls to foster discord and confusion to the point of real-world conflict. Political engagement is a function of democracy; therefore, it stands to reason that disinformation that is polarizing online groups can lead to loss of interest in politics that drives away segments of the population, while motivating others to mobilize, which, as stated, can have adverse real-world consequences, as illustrated by the January 6, 2021 Capitol siege that was carried out in protest against alleged election tampering (Otis, 2021; Tucker et al., 2018). Meanwhile, other evidence suggests that some people have been intimidated from expressing their views online through threatening messages communicated privately and anonymously, even having their physical security threatened in some cases (Lin \& Kerr, 2018).

Despite what has been discussed above regarding state-backed trolls, trolls can act and operate independently anywhere on the web; however, they typically tend to operate in areas where they can remain anonymous (Marwick \& Lewis, 2017). One of the more popular websites in the current alternative media environment, is the website 4chan, an anonymous forum where users create memes, and discuss alternative narratives, such as mass shooting conspiracy theories which are then filtered through Twitter and Facebook, where they are strategically amplified and shaped by the alternative media ecosystem, providing further momentum (CSIS, 2016). Starbird (2017), in her research on how the alternative media environment shapes these conspiracy theories, found that coverage of these theories by the alt-media is based on challenging the corporate (globalist) mainstream narrative and forwarding political agendas that do not fall on the leftright spectrum, such as those by the alt-right, the alt-left, and namely antiglobalism (p. 237). As Internet scholar Whitney Phillips argues, much justification for trolling comes from antipathy towards the mainstream media and its desire for "novelty, spectacle, and poignancy" and the lengths they will go for that (as cited by Marwick \& Lewis, 2017, p. 5). Hence, it is apparent that one of the goals of these trolls is to undermine the mainstream media by providing disinformation for them, and the alt-media, so that together they can amplify it.

In addition to its antipathy towards mainstream media, Marwick and Lewis (2017) have found three other key characteristics contained in content created by 4chan trolls. These are: the preservation of ambiguity, deliberately offensive speech, and the desire for emotional impact (p. 5). The first one, preservation of ambiguity, is perhaps the most important as this characteristic highlights the idea of intentionality, a key element to successful disinformation campaigns. By concealing their intentions, trolls can successfully polarize online vaccination discourses as they combine pseudo-scientific information along with seeds of

The Journal of Intelligence, Conflict, and Warfare Volume 4, Issue 2 
truth to spread disinformation which appears credible but is designed to create disorder and confusion by exploiting underlying identity traits. Furthermore, ambiguity can result in heightened fear during the early periods of crisis situations since public officials have not had time to develop and communicate a credulous response with regards to the situation (Guadagno \& Guttieri, 2019). During this period, ambiguity can result in the spread of rumours which can be difficult to debunk as rumours tend to be shared far more when compared to "boring facts [which] cannot compete with outlandish falsehoods in the popular imaginary" (Guadagno \& Guttieri, 2019, p. 170). The fact that trolls are more likely to take advantage of these ambiguous scenarios is testament to the power that falsehoods can have at opportune times.

In addition to the proliferation of trolls, bots have become the tool of choice for actors, independent or otherwise. Bots can be defined as a form of computational propaganda that distribute false or misleading information over social networking sites for the purposes of manipulating public opinion, influencing political discourse, attacking dissidents, and possibly even manipulating news search rankings (Tucker et al., 2018). Regarding the last point, it is significant to note that one way this is carried out is by linking to false news sites or hyperpartisan alternative media outlets. Bots allow actors to extend their reach in terms of spreading disinformation, due to their ability to disseminate it in "cascading volumes impossible for human actors to produce or vet individually" (CSIS, 2016, p. 10). This works to the anti-vaccination movement's advantage because it allows them to influence more and more users online faster than their narratives can be debunked by organizations dedicated to scientific rationalism or debunking false narratives; thus, this gives disinformation agents the opportunity to set the initial terms of the messaging narrative (Dornan, 2020; Lin \& Kerr, 2018). The ability to achieve initiative was most likely the reason for botnet usage by Kremlin backed agents during the 2016 election.

Research has shown that many of the accounts designated as bots under the IRA were predominantly pro-Trump, with pro-Clinton and anti-Trump tweets being used to a lesser extent (Tucker et al., 2018; Walter et al., 2020). Tweets coming from these accounts were thematically framed in a consistent manner with respect to the candidate's political platforms on various issues, and therefore, utilized "specific language patterns native to and hence, impersonating a target group" (Walter et al., 2020, p. 719). Within the context of vaccine discourse, this meant that pro-Trump accounts spoke about vaccines in ways that were different from anti-Trump accounts, and the difference was congruent with conservatives' likelihood to oppose vaccines and liberals' likelihood to support them (Walter et

The Journal of Intelligence, Conflict, and Warfare Volume 4, Issue 2 
al., 2020). Broniatowski et al. (2018) found in their research on the role of Russian trolls and bots in promoting health content on vaccines over Twitter, that a significant proportion of trolls, sophisticated bots, and content polluter accounts tweeted about vaccination at higher rates compared to the average user. In general, both trolls and sophisticated bots were found to amplify both sides of the vaccine debate, leading to confirmation of a known tactic by Kremlin disinformation campaigns - to foster discord by presenting both sides of the issue, even though there is a "bottom line meaning" (Broniatowski et al, 2018, p. 1382). Such tactics hold dire implications for communities that are vulnerable to 'vaccine hesitancy' due to COVID-19 disinformation/misinformation, such as African Americans and conservatives (Austin et al., 2021; Walter et al., 2020).

One strategic way vaccine hesitancy was promoted in the African American community was through the embedding of trolls within Twitter-based, left leaning online activist circles that were supportive of Black Lives Matter (BLM) (CSIS, 2016). As Walter et al. (2020) found in a sample analysis of themes related to IRA-linked Twitter accounts, trolls attempted to polarize conversations by displaying a series of personas, one of which was an African American and BLM thematic persona that exhibited a balance between vaccination discourses (both pro and anti) and mostly negative content towards corporations and the government. This persona was also linked to a high number of high reach users which was significant for promoting motivational sharing of vaccine disinformation within the community (Austin et al., 2021; Walter et al., 2020). At the same time, during protests against police brutality, right-wing conspiracy theorists hijacked the Twitter hashtag BlackLivesMatter to amplify the reach of conspiracy theories that portrayed the movement as violent and undemocratic (Marwick \& Lewis, 2017). Both the tactics of troll embedding and reframing of BLM protests indicate how Kremlin-sponsored disinformation campaigns (that also amplify conspiracies from far-right influencers) can shift focus at critical periods to target a community on different fronts, in an effort promote social and political polarization. To frame this further within the context of the social media participatory culture and experience, it is necessary to look at the Kremlin's longterm and short-term strategies, as well as their propaganda model for information warfare.

Research has shown that one of the main strategies by foreign state-backed disinformation campaigns is to overwhelm and confuse the targets to the point that even trusted sources are viewed as 'fake news'. The Russian model of propaganda, also known as the "Firehose of Falsehood" (Wardle \& Derakhshan, 2017 , p. 29), is a powerful force in this regard, as it foregoes the necessity of

The Journal of Intelligence, Conflict, and Warfare Volume 4, Issue 2 
strict conventional warfare and instead focuses on a hybrid warfare approach using a combination of military methods and an aggressive disinformation program, such as seen in the 2013 invasion of Ukraine where special forces operations were supported by cyber attacks and disinformation (CSIS, 2016; Freedman et al., 2021). Ukraine's significance in understanding Russia's push towards hybrid warfare stems from the fact that, despite Russia's attempts at manipulation going back to the early 2000s, their campaign success in Ukraine has been their greatest success yet due to their success in controlling the information space and weaponizing information towards its targets (Guess \& Lyons, 2020). Hence, because of instrumental success in disinformation usage, it has recently shifted its focus primarily towards Information Warfare and Influence Operations (IWIO); thus, signifying a shift in strategy towards achieving military objectives without much emphasis on conventional military kinetic force (CSIS, 2016; Lin \& Kerr, 2019).

This shift indicates the power of weaponized information in achieving geopolitical goals. The Russian 'Firehose' model reflects this shift in strategy as it aims to carry out objectives using rapid, continuous, and repetitive messaging that lacks commitment to objective reality, is voluminous across multiple channels, and is inconsistent with its messaging (Guess \& Lyons, 2020; Wardle \& Derakhshan, 2017). This methodology aims to confuse and muddle its targets' thinking, making it difficult for them verify the truth since the underlying idea is to make them believe that there are many different versions of events that are being confirmed by seemingly independent sources connected through vast networks of pro-Kremlin disinformation channels (Wardle \& Derakhshan, 2017, p. 30). Put into play during the influence operation of 2016, the operation evolved throughout the election based on Clinton and Trump's electoral prospects. Eventually, underpinned by the notion that Secretary Clinton was about to win, the campaign focused on undermining her future presidency using covert intelligence efforts, such as cyber activity, along with overt activities involving Russian government agencies, the IRA's troll farms, third party intermediaries, and state-backed media such as Russia Today (Tucker et al., 2018, p. 28). As a report by the GEC indicates, these five activities collectively make up the five pillars of Russia's disinformation and propaganda ecosystem, with activities such as cyber-enabled disinformation and weaponized social media (involving trolls) being the most obscure of all the pillars, providing plausible deniability to the Kremlin and allowing them to deflect criticism while continuing to introduce malicious information through official communications, state media, and proxy sources (third parties) (GEC, 2020, p. $5 \& 8$ ). The most powerful effect of this ecosystem has by far been the media multiplier effect which boosts the reach and

The Journal of Intelligence, Conflict, and Warfare Volume 4, Issue 2 
resonance of its narratives, an opportunistic feature that has allowed the Kremlin to use the COVID-19 pandemic to extend its Active Measure's policy transnationally (GEC, 2020, p. 5). This is significant due to its ability to influence anti-vaccination activists. Taken together, the Firehouse model and the conceptual ecosystem drive the Kremlin's ability to exert global influence, fulfilling Putin's overarching vision, something that will be expanded on briefly below.

Putin's overarching strategy involving IWIO is a strategy that appears to be rooted in maintaining the Leninist tradition of keeping the state locked into perpetual conflict with both his domestic population, and with democratic nations, specifically the U.S (GEC, 2020; Blank, 2013). To that end, their focus on 'informatization' of cyberspace, compared to the U.S' technical definition of it, is seen as a concept that is meant to gear them more towards disrupting an adversary's information, rather than stealing or destroying it (Blank, 2013, p. 32). This suggests that rather than traditional military methods, the concept of information is seen by Russia as more of a way to contest for political influence in the arena of social media, especially when backed by the other four pillars, which signifies an evolution of the Lenin theory of political struggle (Blank, 2013 , p. 33). Not only that, the use of IWIO and disinformation is likely the Kremlin's way of holding onto its illegitimate authority as it seeks to carry out a 'domestic counterinsurgency' against members of its population that seek domestic reforms, as well as allied foreign governments that it sees as attempting to undermine its rule (Blank, 2013, p. 33). As Eurasian Studies professor, Robert E. Hamilton (2019) finds in his study on the Kremlin strategy of perpetual conflict, despite Russia's deteriorated standing in the world, many members of the population laud Putin's attempts to stand up to the West's attempts to allegedly destabilize their state, and that the Kremlin views economic destitution and disrepute as a small price to pay for gaining the attention of the more influential Western nations. To expand on the first point, the strategy is seen as a defensive response to the West's own alleged use of hybrid warfare against the state and the U.S' potentiality to initiate a 'Color Revolution'-a term used to describe of phenomena of U.S intelligence-led coups that are supported by the local population under the guise of resistance to authoritarian rule (Hamilton, 2019 , p. 346). To prevent this from occurring, the Kremlin has opted to strike back by taking advantage of the open nature of the U.S towards political discourse due to its free speech protections (Hamilton, 2019). Thus, because of this geopolitical strategy of perpetual conflict and informatization, a key vulnerability in U.S society has been exploited: the tendency to become easily polarized due to exposure to information efforts that are inflammatory to both

The Journal of Intelligence, Conflict, and Warfare Volume 4, Issue 2 
sides of different social issues; issues that are concurrently framed by individuals that are influenced by varying ideologies (Hamilton, 2019). The next section will examine how social media functions, participatory culture, and user cognition and affect leads to this vulnerability being exploited.

\section{Disinformation spread and resonance through the interplay of cognition, affect, and social identity}

A growing literature of research related to fake news and psychology has shown that, in addition the wide variety of sources that spread disinformation, much engagement and discussion surrounding issues that are prone to manipulation is driven by underlying psychology, at the individual and group-level, and its interaction with social media (Pennycook \& Rand, 2021). According to Pennycook and Rand (2021), belief can be conceptualized in two ways: the first being in terms of the user's overall accuracy in determining what is true or not, and second being the overall belief that a user has towards news in general ( $\mathrm{p}$. 388-389). Conceptualizing this is important as 'truth discernment' is an integral aspect of critically analyzing media; therefore, the failure (or indifference) towards discerning between truthful and false content can be attributed to three fundamental theories that are influential in driving social media participatory behavior and polarization. These are: social identity theory, cultural cognition theory, and affect theory.

Social Identity Theory (SIT) has become an important social psychological theory within the cyber domain, seen as an arena where social groups compete for political influence. Longstanding research regarding this theory has shown that positive self-image is linked to a person's identification with their social group, and the actions their group undertakes will reflect meaningfully on their self-image (Tajfel \& Turner, 1986). This has significant implications for political identity because, as Pereira et al. (2018) state in their 'political identity hypothesis', it would mean that individuals will hold their political identities above ideological values, and as such, are likely to have their beliefs in news stories distorted, so long as they are exposed to positive news regarding the upholding of values (irrespective of ideology) by politicians associated with their ingroup, compared to negative news that is value-undermining towards them ( $\mathrm{p}$. 12). As the results show across all three experiments, the political identity hypothesis was the most supported, compared to the other two (ideological values and confirmation bias); however, as the researchers point out, this does not discount the other two hypotheses completely, but indicates that political identity is more likely to override the other aspects, especially during periods of strong

The Journal of Intelligence, Conflict, and Warfare Volume 4, Issue 2 
polarization and saliency (Pereira et al., 2018, p.55-56). This suggests that polarization arising during critical periods, such as exposure to misinformation and disinformation during an election or pandemic, can contribute to people holding on to social identities through their partisan affiliations; thus, being more susceptible to cognitive biases and processes. Applying the identity model of belief, the researchers further found that belief in the material based on one's political identity allows them to fulfill basic psychological needs such as moral, status, and belonging goals (Pereira et al., 2018, p. 58).

The above likely explains the prevalence of echo chambers and social media algorithms that filter information based on user's preferences, both of which provides the user with information to support their mindset, leaving little room for contravening views or info that could create doubt. These chambers also act as a means in which ideological asymmetries are reinforced as conservatives have value-laden discussions that assert values such as "dogmatism, rigidity, intolerance for ambiguity, and needs for cognitive closure, structure and order, as compared to liberals" (Pereira et al., 2018, p. 60). As a result of this asymmetry, conservatives are more likely to engage, through shares, likes, and comments, with disinformation over social media, than liberals are; however, greater belief superiority is likely at the extreme ends of both sides (Pereira et al., 2018, p. 60-61). This finding was reiterated by Lutzke et al. (2019) in research on priming critical thinking (something that has been shown to prevent engagement with disinformation), who concluded that individuals driven by motivated reasoning and/or a strong conservative identity can resist interventions designed to prime critical thinking to improve resiliency towards climate change disinformation. Thus, while both groups exhibit belief superiority, conservatives are more drawn towards disinformation than liberals are.

In terms of the movement of the bulk of the misinformation/disinformation, research on the social media context suggests that the 'attention economy' aspect of social media may be responsible for the lack of reflective thinking that prevents users from assessing the accuracy of the article. Hence, the bulk of the sharing is likely being driven by non-truth discerning (or inattention to distinguishing between truth or falsehood) intentions (Bennett \& Livingston, 2018; Guess \& Lyons, 2020; Marwick \& Lewis, 2017; Pennycook \& Rand, 2019). However, research has also shown that apolitical material that emotionally arouses or causes affective polarization (explained under 'affect theory') can also lead to the spread of unvalidated material (Pennycook \& Rand, 2019; Pereira et al., 2018); thus, there is no indication that the bulk of material being shared by 
individuals is for identity-related reasons. To understand more about how cognitive processes and biases impact user assessment of disinformation and misinformation, it is important to turn to the theory below.

The next theory, Cultural Cognition Theory (CCT), is an important theory that describes the concept of 'identity-protective' cognition-a well-researched concept in information disorder studies. Research has shown that individuals participate in online engagement through selective exposure of social media curated content, dictated by algorithms (Tucker et al., 2018, p. 18). As a result, discussions of empirical issues are fraught with assessments of information that rely on motivated reasoning and operate from an identity protective standpoint where the goal of protecting one's identity or standing in an affinity group that shares fundamental values generates "motivated cognition related to policyrelevant facts" (Kahan, 2013a, p. 408). This means that propositions that fall in line with the group's dominated thinking will force individuals to defer to the group's perspective due to the unconscious motivation to resist empirical assertions that run contrary to the group's belief, even if the contrary belief is well supported by evidence (Guess \& Lyons 2020; Kahan, 2013a; Kahan, 2017).

In addition, Kahan (2017) further notes that motivated reasoning can also be applied to scientific consensus in the sense that people are more likely to believe a scientist's or expert's point of view if it affirms the group's position they hold, such as whether humans are the cause of global warming (p. 54). Biased sampling towards experts that affirm the anti-vaccination groups views is likely the reason for the spread of health-related misinformation which has led to outbreaks in vaccine-preventable viruses in recent years, suggesting that verifying the accuracy of scientific claims and accepting contravening evidence that is well supported by the scientific community are not priorities for the anti-vaccination movement (Young, 2021; Hotez, 2020). In fact, information that opposes the movement's point of view is far more likely to cement the group's views, giving them a false sense of legitimization as the act of contesting their views is seen as validation of them (Dornan, 2020; Kahan, 2017). However, as Dornan (2020) notes, much of this animosity towards health regulations and science likely stems from uncertainty due to the rapidly evolving nature of COVID-19 research which results in conflicting ideas and models; therefore, contributing to the identityprotective cognition seen in justifying anti-science and vaccine discourse.

The above justification can be observed in the context of COVID-19, Beall et al. (2021) found that cultural cognitive framing of scientific articles on COVID-19

The Journal of Intelligence, Conflict, and Warfare Volume 4, Issue 2 
evokes cultural meaning, activating cultural values, which primes ideologically diverse individuals (particularly conservatives) towards differing levels of perceived validity of COVID-19 articles that are non-ideologically framed. As their results show, liberals who read the technocratically framed article initially, perceived the non-ideological COVID-19 article with far less validity; whereas, for conservatives there was only a slight increase, illustrating how worldviews shaped how both groups viewed the scientific and factually accurate article. Those with communitarian values, such as those liberals hold, are likely to view the use of technology as risk aversive, while conservatives who are more individualistic are likely to view it as a sign of ingenuity, which leads to the differences in perceived validity. Framing appeared to have a small impact on discussions of COVID-19 zoonotic origins; however, Beall et al. (2021) note that this was likely due to the increasing debate on preventative measures that became the prime focus soon after the pandemic was declared. Thus, as this research encapsulates, CCT is significant in understanding how anti-vaccinationists may perceive COVID-19 literature that is unequivocal to their worldview.

The final theory, 'Affect Theory', is an under-utilized theory in the field of misinformation studies, but nevertheless, one that is just as significant in applying to this theoretical framework. Researchers have recently begun to realize the effect of emotion on user susceptibility towards fake news, indicating a shift in focus from research that has largely concentrated on the use of reasoning (analytic thinking) and deliberation in the development of accurate beliefs up until now (Bakir \& McStay, 2018; Martel et al., 2020). This has led to more research on the phenomena of affective polarization, which is distinct from ideological polarization. Affective polarization, defined as the extent to which supporters of different political parties dislike the other party and its supporters, can occur when political actors deliberately disseminate disinformation that leaves readers in disarray, leading to political apathy, lowered levels of trust in institutions, and greater support for radical political parties as the user becomes driven by sentiment and fantasies of what a good life entails (i.e., being apart of a community of like-minded and supportive individuals) (Tucker et al., 2018; European Foundation for South Asian Studies [EFSAS], 2021). In this sense, the fantasy of a good life clashes with the need for credibility, and disinformation campaigns are more likely to succeed because they "effectively exploit our cruel attachments to a good life" (Young, 2021, p. 3). In some countries such as Nepal and India, this aspect has been exemplified in discrimination meant to foment hatred and violence towards Christians and other religious minorities, stigmatizing them as subversive groups that are intent on fragmenting Hindu 
society through conversion and spreading of COVID-19 (United Nations Geneva, 2021). This indicates that when conspiracy narratives intersect with violent extremist discourse, a dangerous mechanism can be established; one that is built upon creating fear through ideas such as superiority versus inferiority, imminent threat, and an existential crisis facing the in-group (EFSAS, 2021).

At the more moderate end of the scale, feelings of frustration towards institutions responsible for health communications can be expected. As stated, before constant rational examinations and incoming information can lead to less certainty, especially considering the currently iterative process of expanding COVID-19 literature and evaluating its knowledge base (Dornan, 2020; Temmerman et al., 2018). Because of this uncertainty, individuals are left vulnerable to alt-media outlets that exploit this state of mind in three ways: proliferating narratives that further fuel uncertainty and confusion, ultimately leading to democratic fatigue and immobility; 'politicization of expertise' which renders all domain-specific knowledge, as well as science, subject to constant debate; and finally, 'cultivation of conspiracy', as means to help recreate order within the chaos of claims and counterclaims (Temmerman et al., 2018, p. 2). It is within this vacuum that users become guided by emotions that switch between resentment and contentment due to exposure to misinformation and disinformation designed to spur affective polarization. As a result, affect theory becomes relevant in understanding how disinformation and misinformation are spread.

\section{Recommendations}

To better handle the threat posed by disinformation spread by the triumvirate and mitigate its effect on fueling the COVID-19 anti-vaccination movement, a number of recommendations must be considered based on the need for improvements in scientific communication of health-related news, to digital media literacy skills, and identifying and countering IWIOs. The most important dimensions of the phenomenon relate to scientific communication of critical health related news and digital media literacy; therefore, these recommendations will be delved into first before discussing the final one.

\section{Critical health care communications}

The prevalence of information disorder during the COVID-19 pandemic demands a change in how scientific news and risks are communicated to target populations. As Kahan (2013b) finds in his article on the problems associated with science communication regarding childhood vaccination, much controversy

The Journal of Intelligence, Conflict, and Warfare Volume 4, Issue 2 
around decision-relevant science stems from a lack of emphasis on protecting citizens from influences that create unfounded fears of vaccines. The most significant of these is empirically uninformed risk communication that risks conflating vaccine hesitancy with scepticisms of evolution and climate change, as well as making misleading statements of fear and distrust of vaccination, which has the unintended consequence of creating further fear and distrust (Kahan, 2013b, p. 54). Both effects risk increasing polarization through cultural cognition, which results in viewing the issue through cultural lenses, and hence, must be considered when relaying info about COVID-19 decision-relevant science (Broniatowski, et al., 2020, p. 618). Despite the scarce research on science communication, Kappel and Holmen (2019), developed a conceptual framework on science communication based off the existing literature, and identified eight aims that guide communication, as well as two paradigms: the dissemination paradigm and the public participation paradigm. The dissemination paradigm posits a one-way method of transmission involving topdown communication from formal education (schools) or mass media, to the public who are meant to be passive listeners (Kappel \& Holmen, 2019). The public participation paradigm, on the other hand, posits a multi-way method of transmission that facilitates dialogue and possibly deliberation between public representatives, experts, and policy makers. Each paradigm is meant to focus on certain aims over others (Kappel \& Holmen, 2019, p. 2-3). In terms of mitigating the spread and effectiveness of anti-vaccination misinformation and disinformation designed to create ideological opposition to vaccination strategies, the best recommendation would be for policy makers and scientific institutions to enact a communicative model based on the public participation paradigm, with an emphasis on its primary aims, as well as aims that are in common with the dissemination paradigm. This includes improving beliefs about science, generating public epistemic and moral trust (i.e., trust in the mechanisms of scientific institutions, and trust that they are acting in a moral manner), collecting, and making use of local knowledge, and enhancing democratic legitimacy of funding, governance and application of science or specific segments of science (Kappel \& Holmen, 2019, p. 6-9). Essentially, a multidimensional strategy based on evidence-informed communication and an array of independent experts and influencers at different levels will be required to put the paradigmatic frame and its aims into effect (Kappel \& Holmen, 2019; Rzymski et al., 2021).

The Journal of Intelligence, Conflict, and Warfare Volume 4, Issue 2 


\section{Critical media literacy skills}

The next recommendation involves improving critical media literacy skills, with an emphasis on understanding social media's harmful effects so that users may be less likely to share disinformation, even if they believe it is fake. As research shows, the accuracy of content has no bearing on the desire to share it, since users are far more willing to share content in which they can identify headlines as being false, compared to those that are true-this is particularly the case for political headlines and headlines about COVID-19 (Pennycook \& Rand, 2021). Furthermore, even when users struggle to successfully discern the level of truth presented in an article, mental intuitive shortcuts (or heuristics) can trigger belief due to exposure to emotionally evocative headlines, familiarity with the false headlines, and claims from influencers that the user identifies with, which altogether suggests that users are viewing the disinformation through identity lenses and/or paying little attention towards critically examining its veracity (Bakir \& Mcstay, 2018; Li \& Su, 2020; Pennycook \& Rand, 2021). Thus, greater emphasis should be placed on developing critical media literacy skills that can enhance reasoning and understanding of disinformation tactics, making users less susceptible to sources of affective and ideological polarization. Education should revolve around sources such as: 'clickbait' articles that fuel ad revenue, false claims from elites, amateur journalists that peddle in disinformation, digital echo chambers, filter bubbles, and algorithm-based automated content designed to maximize emotional contagion (algo-journalism) (Bakir \& Mcstay, 2018; Dornan, 2020; Krafft \& Donovan, 2020). Learning how to identify the different categories of disinformation (rumours, conspiracy theories, fake websites, etc.) can also be helpful (Guadagno \& Guttieri, 2019). At the same time, it is necessary to ensure that users understand why they cling to misinformation in the face of solid evidence and expert opinion-this means having a groundwork understanding of the role of 'hot cognition' and the directional biases they produce such as confirmation bias (Young, 2021). Finally, and most importantly, the approach must be underpinned by the fundamental understanding that users are not passive consumers of disinformation, and even a small exposure can likely lead to a desire for more; a fact that many disinformation campaigns backed by authoritarian regimes take advantage of to expand the reach of their weaponized, identity-laden narratives across networks (Bastick, 2021; CSIS, 2016; Freedman et al., 2021; Krafft \& Donovan, 2020; Lin \& Kerr, 2019; Wardle \& Derakhshan, 2017).

The Journal of Intelligence, Conflict, and Warfare Volume 4, Issue 2 


\section{Countering foreign state IWIOs}

The final recommendation at the political level relates to countering foreign statebacked information campaigns. Any effective solution in this regard must account for the unique nature of IWIO and knowing how to identify it from ordinary forms of political debates. IWIOs have three characteristics which distinguish them. These are: 1) propagation by third parties that have something to gain, 2) depreciation of democratic legitimacy, and 3) the proliferation of automatic social chat-bots that spread differing political messages en masse (Lin \& Kerr, 2019). Once an IWIO has been identified, the next step is to counter it. However, this is easier said than done since the onslaught nature of the Russian propaganda model poses immense challenges towards curbing the cascading waves of disinformation, leaving the only other solutions to be putting more pressure on social media companies to enforce their terms of service agreements, and developing a public inoculation approach in the same vein as what has been recommended above (Lin \& Kerr, 2019, p. 23-24). CSIS (2016) advocates the use of stopfake.org which is the largest international hub for Kremlin propaganda, dedicated to monitoring and identifying geotargeted narratives, debunking them, and archiving cases. It also raises public awareness for domestic and international audiences. In essence, this recommendation is largely contingent on the first two; thus, the best geopolitical solution to foreign exploitation of social cleavages involves increasing civilian resiliency to disinformation (Freedman et al., 2021).

\section{Conclusion}

In essence, identity politics have created a new wave of post-truth discursive interpretations of events and scientific information from responsible media and democratic institutions. This has paved the way for exploitation by both state and non-state actors. Social media, once touted as a tool of liberation, has become a means to exert meaningful political influence through disinformation and misinformation that appeals to users' sense of identity and cultural cognition forcing them to place more emphasis on zero-sum, us versus them exclusionary identity politics, to the detriment of inclusive identity politics which is necessary for conflict resolution and reform (Kharroub, 2019, pp. 141-142). Due to the minimal tools required and its cost effectiveness, authoritarian regimes such as those in the Middle East have begun using disinformation campaigns to crack down on dissent in their countries while fulfilling their broader geopolitical goals that are transnational in nature (Kharroub, 2019). The most conspicuous of this manifested itself through the 2016 election, which raised awareness of Russia's 
complicity in interfering in foreign elections through its campaigns intended to sow discord and confusion. The ultimate effect of this has been the use of identity-based movements such as the COVID-19 anti-vaccination movement that relies on anti-vaccination narratives intersected with ideological movements such as Black Lives Matter to promote disinformation against COVID-19 epidemiology and scientific institutions. Furthermore, the tendency of disinformation to become decontextualized as it crosses platforms means that in other geographic contexts, COVID-19 disinformation can be reproduced to include narratives based on markers such as gender as well. For instance, research currently shows that stronger levels of immuno-reactivity in females can result in adverse reactions to vaccines that are more frequent and serious in them compared to men (Corda et al., 2021). Disinformation agents that use this information as apart of their narratives can create turmoil in at risk communities and geographic regions where vaccine distribution rates are already low. It is evident that the post-truth situation, created by Trump's lambasting of traditional journalism and his rhetoric involving fake news and alternative facts, has given serious momentum to discursive interpretations of events by multiple movements through conspiracy theories, rumours, and other disinformation spread. As a result, the anti-vaccination movement while small, nevertheless has the ability to enact immense influence on public consciousness as a result of social media's functionality and its ability to contribute to identity-based information disorder. Furthermore, due to the reverberating loop of amplification by the triumvirates, the movement's goals in achieving reach and resonance are magnified significantly.

This article has raised points on the strategies, tactics, and types of disinformation and how they can interact with users, fueling their beliefs and/or their desire to engage with the material. The next step is to take the necessary measures to curb the anti-vaccine movement's strategies, while placing such counteracting strategies in a greater context that involves aid at all levels. A comprehensive inter-agency framework can include: federal geopolitical strategies created and evaluated for the purposes of addressing foreign state intrusion, to technological strategies aimed at greater enforcement of terms of services on social media platforms, partnerships with third party organizations created for the purpose of debunking and fact-checking disinformation that is going viral and being manipulated by disinformation agents, and finally the possibility of implementing the public participation paradigm through the use of Consensus Conference which enlists members of the public to act as representatives of their affiliated groups in order to deliberate about scientific topics with experts in a forum that is regulated. This holds much promise since it allows public members

The Journal of Intelligence, Conflict, and Warfare Volume 4, Issue 2 
to break away from the social media arena where discussions are fraught with biases and heightened emotions, to a more appropriate setting where they can expand their domain specific knowledge regarding the topic and have concerns alleviated. Unfortunately, before this can be done, more empirical research needs to be conducted on developing indicators of success in achieving the aims set out and establishing metrics for concepts such as moral and epistemic trust.

There is also a need to improve on existing capabilities if Western governments want to compete with Russia in geopolitical information warfare. Russia has improved its non-kinetic capabilities, particularly those involving IWIO, to the point that its information and cyber capabilities are now on par with its conventional methods when it comes to extending state influence over geographic spaces. While Russia currently has the edge in information warfare due to their years of experience in honing it, Western democracies must follow suit and begin to allocate resources towards the development of their own 'cyber troops' with the intention of working their way up until their efforts in countering Kremlin propaganda are at an equivocal level. This also means that institutes dedicated to national security must find a way to develop their own framework to merge theory and practise to 'dull' the weaponized impact of Kremlin disinformation efforts. Ultimately, a combination of critical literacy, public participation, public-private collaboration, and defensive capabilities is what will stem the tide of misinformation and disinformation distribution by actors with nonchalant intents, and those with malevolent ones.

The Journal of Intelligence, Conflict, and Warfare Volume 4, Issue 2 


\section{References}

Austin, W. E., Borah, P., \& Domgaard, S. (2021). COVID-19 Disinformation and political engagement among communities of color: The role of media literacy. The Harvard Kennedy School Misinformation Review, 1(7), 1-15. https://doi.org/10.37016/mr-2020-58

Bakir, V., \& McStay, A. (2018). Fake news and the economy of emotions. Digital Journalism, 6(2), 154-175. https://doi.org/10.1080/21670811.2017.1345645

Beall, M. J., Casola, R. W., Peterson, N. M., Larson, R. L., Carr, A.W., Seekamp, E., Stevenson, T. K., \& Jackson, B. S. (2021). Cultural cognition and ideological framing influence communication about zoonotic disease in the era of COVID-19. Frontiers in Communication, 6, 1-17. https://doi.org/10.3389/fcomm.2021.645692

Beauchamp, Z. (2016, November 9). Donald Trump's victory is part of a global white backlash. Vox. https://www.vox.com/world/2016/11/9/13572174/president-electdonald-trump-2016-victory-racism-xenophobia

Bennett, W. L., \& Livingston, S. (2018). The disinformation order: Disruptive communication and the decline of democratic institutions. European Journal of Communication, 33(2), 122-139. https://doi.org/10.1177/0267323118760317

Bernard, R., Bowsher, G., Sullivan, R., \& Gibson-Fall, F. (2021).

Disinformation and epidemics: Anticipating the next phase of biowarfare. Health Security, 19(1), 3-12. https://doi.org/10.1089/hs.2020.0038

Bevensee, E., \& Ross, R. A. (2019). The alt-right and global information warfare. 2018 IEEE International Conference on Big Data (Big Data), 1, 4393-4402. https://doi.org/10.1109/BigData.2018.8622270

Blank, S. (2013.) Russian information warfare as domestic counterinsurgency. American Foreign Policy Interests: The Journal of the National Committee on American Foreign Policy, 35(1), 31-44. http://dx.doi.org/10.1080/10803920.2013.757946 
Broniatowski, D., Jamison, M. A., Qi, S., AlKulaib, L., Chen, T., Benton, A., Quinn, C. S., \& Dredze, M. (2018). Weaponized health communication: Twitter bots and Russian trolls amplify the vaccine debate. American Journal of Public Health (AJPH), 108(10), 1378-1384.

https://doi.org/10.2105/AJPH.2018.304567

Broniatowski, D., Quinn, C.S., Dredze, M., Jamison, M.A. (2020). Vaccine communication as weaponized identity politics. American Journal of Public Health (AJPH), 110(5), 617-618.

https://doi.org/10.2105/AJPH.2020.305616

Canadian Security Intelligence Service (CSIS). (2016). Who said what? The Security Challenges of Modern Disinformation. World Watch: Expert Notes. https://www.canada.ca/content/dam/csisscrs/documents/publications/disinformation_post-report_eng.pdf

Corda, V., Murgia, F., \& Monni, G. (2021). COVID-19 vaccine: The gender disparity. Journal of Perinatal Medicine, 49(6), 723-24. https://doi.org/10.1515/jpm-2021-0246

Doherty, C., \& Kiley, J. (2016, June 22). Key facts about partisanship and political animosity in America. Pew Research Center. https://www.pewresearch.org/fact-tank/2016/06/22/key-factspartisanship/

Dornan, C. (2020). Science disinformation in a time of pandemic. Public Policy Forum. https://ppforum.ca/wpcontent/uploads/2020/06/ScienceDisinformation-PPF-June2020-EN.pdf

European Foundation for South Asian Strategic Studies (EFSAS). (2021, June). The role of fake news in fueling hate speech and extremism online; Promoting adequate measures for tackling the phenomenon. https://www.efsas.org/publications/study-papers/the-role-of-fake-newsin-fueling-hate-speech-and-extremism-online/

Feron, E., \& Lefort, B. (2018). Diasporas and conflicts - Understanding the nexus. Diaspora Studies, 12(1), 34-51. https://doi.org/10.1080/09739572.2018.1538687 
Freedman, J., Gjorv H. G., \& Razakamaharavo, V. (2021). Identity, stability, hybrid threats, and disinformation. Icono 14, 19(1), 38-69. https://doi.org/10.7195/ri14.v19i1.1618

Global Engagement Center (GEC). (2020). GEC special report: Pillars of Russia's disinformation and propaganda ecosystem. U.S. Department of State. https://www.state.gov/russias-pillars-of-disinformation-andpropaganda-report/

Guadagno, E. R., \& Guttieri, K. (2019). Chapter 11 - Fake news and information warfare: An examination of the psychological processes from the digital sphere to the real world. In I. Chiluwa. Handbook of research on deception, fake news, and misinformation online (pp. 167191). IGI Global. https://doi.org/10.4018/978-1-5225-8535-0

Guess, A. M., \& Lyons, B. A. (2020). Misinformation, disinformation, and online propaganda. In N. Persily \& J. A. Tucker. Social media and democracy: The state of the field and prospects for reform (pp. 10-33). Cambridge University Press. https://doi.org/10.1017/9781108890960

Hotez, J. P. (2020). Anti-science extremism in America: Escalating and globalizing. Microbes and Infection, 22, 505-507. https://www.sciencedirect.com/science/article/pii/S1286457920301581

Kahan, M. D. (2013a). Ideology, motivated reasoning, and cognitive reflection. Judgment and Decision Making, 8(4), 407-424. http://journal.sjdm.org/13/13313/jdm13313.pdf

Kahan, M. D. (2013b). A risky science communication environment for vaccines. Science, 342(53), 53-54. https://www.science.org/doi/10.1126/science.1245724

Kahan, M. D. (2017). Misconceptions, misinformation, and the logic of identity-protective cognition. The Cultural Cognition Project at Yale Law School. http://www.culturalcognition.net/browsepapers/misconceptions-misinformation-and-the-logic-of-identityprot.html

Kappel, K., \& Holmen, S.J. (2019). Why science communication, and does it work? A taxonomy of science communication aims and a survey of the 
empirical evidence. Frontiers in Communication, 4(55), 1-12. https://doi.org/10.3389/fcomm.2019.00055

Kelvin, M. (2021). Alternative media framing of COVID-19 risks. Sociology and Criminology - Open Access, 9(5). https://www.longdom.org/openaccess/alternative-media-framing-of-covid19-risks.pdf

Kharroub, T. (2019). Identity politics 2.0: Cyber geopolitics and the weaponization of social media. In Z. Azzam \& I. K. Harb. The Arab world beyond conflict (pp. 139-149). Arab Center Washington DC. http://arabcenterdc.org/policy_analyses/identity-politics-2-0-cybergeopolitics-and-the-weaponization-of-social-media/

Krafft, P. M., \& Donovan, J. (2020). Disinformation by design: The use of evidence collages and platform filtering in a media manipulation campaign. Political Communication, 37(2), 194-214, https://doi.org/10.1080/10584609.2019.1686094

Li, J., \& Su, M. (2020, April). Real talk about fake news: Identity language and disconnected networks of the US public's "fake news" discourse on Twitter. Social Media + Society. https://doi.org/10.1177/2056305120916841

Lin, K., \& Kerr, J. (2019). On cyber-enabled information warfare and information operations. Oxford handbook of cybersecurity 2019. https://papers.ssrn.com/sol3/papers.cfm?abstract_id=3015680

Longley, R. (2020, October 14). What is Astroturfing in politics? Definitions and examples. ThoughtCo. https://www.thoughtco.com/what-isastroturfing-definition-and-examples-5082082

Lutzke, L., Drummond, C., Slovic, P., \& Arvai, J. (2019). Priming critical thinking: Simple interventions limit the influence of fake news about climate change on Facebook. Global Environmental Change, 58, 1-8. https://doi.org/10.1016/j.gloenvcha.2019.101964

Martel, C., Pennycook, G., \& Rand, G.D. (2020). Reliance on emotion promotes belief in fake news. Cognitive Research: Principles and Implication, 5(47), 1-20. https://doi.org/10.1186/s41235-020-00252-3 
Marwick, A., \& Lewis, R. (2017). Media manipulation and disinformation online. Data and Society Research Institute. https://datasociety.net/library/media-manipulation-and-disinfo-online/

Nelson, L. (2016, September 1). “America First”: Donald Trump's slogan has a deeply bigoted backstory. Vox. https://www.vox.com/2016/7/20/12198760/america-first-donald-trumpconvention

Otis, L. C. (2021, January 13). Trump's 5-year campaign of lies led to the Capitol attack. And we just let it happen. USA Today. https://www.usatoday.com/story/opinion/2021/01/13/trumpdisinformation-campaign-led-to-capitol-coup-attemptcolumn/6639309002/

Pennycook, G., \& Rand, G.D. (2021). The psychology of fake news. Trends in Cognitive Sciences, 25(5), 388-402. https://doi.org/10.1016/j.tics.2021.02.007

Pereira, A., Harris, E., Van Bavel, J. J. (2018, September 11). Identity concerns drive belief: The impact of partisan identity on the belief and dissemination of true and false news. PsyArXiv Preprints. https://doi.org/10.31234/osf.io/7vc5d

Rzymski, P., Borkowski, L., Drąg, M., Flisiak, R., Jemielity, J., Krajewski, J., Mastalerz-Migas A., Matyja A., Pyrć, K., Simon, K., Sutkowski, M., Wysocki, J., Zajkowska J., \& Fal, A. (2021). The strategies to support the COVID-19 vaccination with evidence-based communication and tackling misinformation. Vaccines, 9(2), 1-9. https://doi.org/10.3390/vaccines9020109

Ragazzi, F. (2012). Diaspora: The politics of its meanings. International Political Sociology, 6(1), 107-111. https://doi.org/10.1111/j.17495687.2011.00152_5.x

Hamilton, E. R. (2019). Russia's attempts to undermine democracy in the West: Effects and Causes. Orbis, 63(3), 334-348. https://doi.org/10.1016/j.orbis.2019.05.009.

Starbird, K. (2017). Examining the alternative media ecosystem through the production of alternative narratives of mass shooting events on Twitter. 
Proceedings of the International AAAI Conference on Web and Social Media, 11(1), 230-239.

https://ojs.aaai.org/index.php/ICWSM/article/view/14878

Temmerman, M., Moernaut, R., Coesmans, R., \& Mast, J. (2018). Post-truth and the political: Constructions and distortions in representing political facts. Discourse, Context \& Media, 27, 1-6. https://doi.org/10.1016/j.dcm.2018.10.002

Tajfel, H., \& Turner, J. C. (1986). The social identity of intergroup relations. In S. Worchel \& W. G. Austin (Eds), Psychology of intergroup relations (pp. 7-24). Hall Publishers, Chicago.

Tucker, A.J., Guess, A., Pablo, B., Vaccari, C., Siegel, A., Sanovich, S., Stukal, D., \& Nyhan, B. (2018, March). Social media, political polarization, and political disinformation: A review of the scientific literature. William and Flora Hewlett Foundation. https://www.hewlett.org/wpcontent/uploads/2018/03/Social-Media-Political-Polarization-andPolitical-Disinformation-Literature-Review.pdf

United Nations Geneva. (2021, May 28). Disinformation and hatred against religious minorities in India and Nepal. World Evangelical Alliance (WEA): United Nations Engagement. https://un.worldea.org/india-andnepal-disinformation-and-hatred-against-religious-minorities/

Walter, D., Ophir, Y., Jamieson H. K. (2020). Russian Twitter accounts and the partisan polarization of vaccine discourse, 2015-2017. American Journal of Public Health (AJPH) Open-Themed Research, 110(5), 718724. https://doi.org/10.2105/AJPH.2019.305564

Wardle, C., \& Derakhshan, H. (2017, September 27). Information disorder: Toward an interdisciplinary framework for research and policy making. Council of Europe. https://edoc.coe.int/en/media/7495-informationdisorder-toward-an-interdisciplinary-framework-for-research-andpolicy-making.html

Young, C. J. (2021). Disinformation as the weaponization of cruel optimism: A critical intervention in misinformation studies. Emotion, Space, and Society, 38, 1-7. https://doi.org/10.1016/j.emospa.2020.100757 


\section{(c) (i) $(\Theta$}

EY NO ND This work is licensed under a Creative Commons Attribution-NonCommercial-NoDerivatives 4.0 International License.

(C) (AMAN BAJWA, 2021)

Published by the Journal of Intelligence, Conflict, and Warfare and Simon Fraser University

Available from: https://jicw.org/ 